\title{
O papel dos agentes na comunidade de artesãos em Três Lagoas-MS, como instrumentos impulsionadores do desenvolvimento local
}

The role of the agents in the artisans' community at Três Lagoas, city of Mato Grosso do Sul - Brazil, as impulsive human tools to the local development Le rôle des agents dans la communauté des artisans à Três Lagoas, ville de Mato Grosso do Sul - Brésil, comme des instruments encourageants au développement local El papel de los agentes en la comunidad de artesanos en Três Lagoas, Mato Grosso do Sul, como instrumentos impulsadores del desarrollo local

\author{
Elisângela de Aguiar Alcalde* \\ Cleonice Alexandre Le Bourlegat** \\ Maria Augusta de Castilho**
}

Recebido em 30/12/2006; revisado e aprovado em 14/5/2007; aceito25/6/200.

\begin{abstract}
Resumo: A pesquisa realizada analisou os agentes na comunidade de artesãos como instrumentos impulsionadores do desenvolvimento local. A construção dos conceitos de desenvolvimento local e políticas públicas é um processo amplo e de debate permanente como nova maneira de promover o desenvolvimento, contribuindo para a melhoria da qualidade de vida das comunidades, com capacidade de suprir suas necessidades mais imediatas, e de incrementar o intercâmbio externo por meio de ações comunitárias conjuntas. Para tanto, se fez necessário conhecer o perfil da comunidade estudada, pois sem conhecer a comunidade em questão, bem como sua realidade se tornaria difícil visualizar os caminhos a serem seguidos. Justifica-se, portanto, a necessidade de aprofundar o assunto mediante a sua relevância, pois a essência do trabalho vai ao encontro das propostas conceituais do desenvolvimento local.
\end{abstract}

Palavras-chave: artesãos; comunidade; territorialidade.

Abstract: This research evaluated the agents in the artisans' community as impulsive human tools to the local development. The construction of concepts about local development and public politics is an ample process of permanent discussion. It constitutes a new way to promote the development because it contributes to the improvement of the communities' life quality, with capacity to supply their immediate necessities and to increase the external exchange through conjunct community actions. For this, it was necessary to know the considered community aspects, since if it hasn't had knowledge about this community and its reality, it would be difficult to visualize the ways to be followed. Therefore, it justifies the need to make a profound study of this subject due to its importance, since the work essence comes across the concepts of local development.

Key words: artisans; community; territoriality.

Résumé: Cette recherche a évalué les agents dans la communauté des artisans comme des instruments encourageants au développement local. La construction des concepts de développement local et des politiques publiques est un processus ample de discussion permanente. C'est une nouvelle manière de promouvoir le développement contribuant à l' amélioration de la qualité de vie des communautés, ces dernières ayant la capacité de satisfaire leurs nécessités plus immédiates et améliorer les échanges externes par le moyen de actions communautaires. Pour cela, il a fallu connaître le profil de cette communauté, parce que sans connaître la communauté et sa réalité, il serait difficile visualiser les chemins à poursuivre. Par conséquent, il se justifie le besoin d'approfondir le sujet dû à son importance, puis que l'essence du travail va à la rencontre des propositions conceptuelles du développement local.

Mots-clés: artisans; communauté; régionalisme.

Resumen: La pesquisa realizada analizó los agentes en la comunidad de artesanos como instrumentos impulsadores del desarrollo local. La construcción de los conceptos de desarrollo local y políticas públicas es un proceso amplio y de debate permanente como nueva manera de promover el desarrollo, contribuyendo para la mejoría de la cualidad de vida de las comunidades, con capacidad de suprir sus necesidades más inmediatas, y de incrementar el intercambio externo por medio de acciones comunitarias conjuntas. Para tanto, se hizo necesario conocer el perfil de la comunidad estudiada, pues sin conocer la comunidad en cuestión, así como su realidad sería difícil visualizar los caminos a ser seguidos. Se justifica, por lo tanto, la necesidad de profundar el asunto mediante su relevancia, pues la esencia del trabajo va al encuentro de las propuestas conceptuales del desarrollo local.

Palabras-clave: artesanos; comunidad; territorialidad.

\footnotetext{
* Mestranda de Desenvolvimento Local - Universidade Católica Dom Bosco.

** Professoras Doutoras do Programa de Mestrado em Desenvolvimento Local - Universidade Católica Dom Bosco.
} 


\section{Introdução}

Os primeiros artesãos surgiram no período neolítico (6.000 A.C) quando o homem aprendeu a polir a pedra e a fabricar a cerâmica como utensílio para armazenar e cozinhar alimentos; posteriormente descobriu a técnica de tecelagem das fibras animais e vegetais. O regime de trabalho que reúne as diferentes técnicas manuais de produção só recentemente ganhou nome, embora à história assinale a presença de objetos feitos à mão em todas as épocas e nas mais variadas culturas.

A atividade artesanal está ligada aos recursos naturais, do estilo de vida e ao grau de comércio com as comunidades vizinhas. A aprendizagem do trabalho artesanal é adquirida de maneira prática e formal, por meio de oficinas ou na vivência do indivíduo com o meio artesanal, em que o aprendiz maneja a matéria-prima e as ferramentas imitando os mais entendidos no ofício.

Desta forma, o objeto de estudo deste trabalho refere-se à comunidade de Artesãos do Município de Três Lagoas, composta por trinta e três artesãos e que, inicialmente, teve como parceiros a CACB - Confederação das Associações Comercial do Brasil, a ACITL Associação Comercial e Industrial de Três Lagoas, o SEBRAE - Serviço Brasileiro de Apoio às Micro e Pequenas Empresas e a PM - Prefeitura Municipal, via Secretaria de Turismo e Cultura, por meio da implantação no município do Projeto Empreender, constituindo inicialmente por cinco núcleos.

Nesse cenário, implantou-se, no ano de 2002 no município de Três Lagoas/MS, dentro do Projeto Empreender o núcleo de artesanato, tendo como objetivo promover o associativismo e o cooperativismo como alternativa de união dos artesãos para a sustentabilidade e o desenvolvimento do grupo. Segundo a ACISAP - Associação Comercial e Industrial e de Serviços de Santo Antônio da Patrulha (2007), o Projeto Empreender apresenta uma proposta inovadora, uma vez que estimula os empresários a se auto-organizarem e a determinarem as suas demandas. O objetivo do projeto é elevar a competitividade das Micro e Pequenas empresas, promovendo o desenvolvimento organizacional das Associações Empresariais parceiras. Essa ação conjunta de políticas públicas, representadas pelos agentes de desenvolvimento, pressupõe a assimilação de novas formas de planejamento e gestão. Implica apoiar programas de capacitação para a formação de multiplicadores de iniciativas, lideranças e agentes locais que incorporem a perspectiva do desenvolvimento local integrado e sustentável.

Assim, analisaram-se os agentes na comunidade de artesãos como instrumentos impulsionadores do desenvolvimento local, por meio de um levantamento do histórico da comunidade estudada, suas características, ações e etapas de consolidação.

No estudo foram utilizadas duas fontes distintas: uma de dados primários, coletados através de questionários com os artesãos no seu espaço físico de trabalho, e a outra, de dados secundários, oriundos de documentos, pesquisa bibliográficas em livros, periódicos, revistas, entre outros.

\section{Desenvolvimento local, território, territorialidade e políticas públicas}

\section{- Desenvolvimento local}

Desenvolvimento significa melhoria na qualidade de vida das pessoas. Analisando o fator econômico, devem-se agregar outros fatores como: o crescimento do capital social, a conquista da boa governança, dentre outros.

Pereira (1985) aponta que o desenvolvimento é um processo de transformação econômica, política e social, na qual o padrão de vida da população passa por um crescimento significativo tornando-se automático e autônomo. O desenvolvimento não pode ser encarado de forma integral. As metas técnicas são absolutamente necessárias e respeitadas, porém devem ser encaradas como os méis para o alcance do objetivo final, que é, acima de tudo, a ampliação das oportunidades reais dos seres humanos de desenvolverem suas habilidades e potencialidades. Assim, o ser humano não é só um meio do desenvolvimento, mas sim, sua finalidade última.

Kliksberg (2003, p.110) assinala que: “junto com o crescimento econômico, surge 
a necessidade de alcançar o desenvolvimento social, melhorar a eqüidade, fortalecer a democracia e preservar os equilíbrios do meio ambiente".

Para Fragoso (2005), o conceito de desenvolvimento local seria um assunto para muitos estudos, mas, pode-se afirmar que se trata da possibilidade das populações poderem expressar uma idéia de futuro para um território, concretizando ações que possam ajudar na construção ou na reconstrução desse futuro.

Para a concretização desses conceitos, faz-se necessário construir um processo coletivo e altamente educativo, articulado com a participação dos moradores do local, bem como de agentes e de entidades externas.

$\mathrm{O}$ desenvolvimento local, na concepção de Martins (2002, p.51), se constitui em um "evento sui generis resultante do pensamento e da ação à escala humana, que confronta o desafio de enfrentar problemas básicos e alcançar níveis elementares e autoreferenciados de qualidade de vida na comunidade".

Martin (1999) apud Martins (2002) completa o pensamento anterior afirmando que, o desenvolvimento local igual à escala humana deve ser interpretado como a satisfação das necessidades humanas essenciais através da efetiva participação dos atores, ou seja, de cada pessoa. Esse talvez seja o maior desafio do desenvolvimento local.

\section{- Território}

Diversos trabalhos sobre o desenvolvimento local têm demonstrado a importância da relação entre território e comunidade. Entende-se que, os territórios juntamente com as comunidades podem constituir identidades, isso acontece à medida que as pessoas estão estruturalmente localizadas a partir de suas relações primárias ou secundárias a que se relacionam.

Recentemente, diversas áreas do conhecimento adotaram o território como conceito essencial em suas análises. Todavia, o conceito de território é utilizado como uma dimensão das relações sociais, enquanto na verdade, o território é multidimensional, constituindo-se em uma totalidade. Segundo Corrêa (1994, p. 251), o termo "território deriva do latim terra e torium, significando a terra pertencente a alguém. Pertencente, entretanto, não se vincula necessariamente à propriedade da terra, mas a sua apropriação".

De acordo com Raffestin (1993, p. 144), o território é "um espaço onde se projetou um trabalho seja energia e informação, e que, por conseqüência, revela relações marcadas pelo poder [...] o território é a prisão que os homens constroem para si. [...]" O território se apóia no espaço, mas não é o espaço.

Heidrich (1998), ao se referir à constituição do território, afirma que a distinção do espaço em esfera histórica começa a partir da demarcação do mesmo, isto é; por sua apropriação como território, por um lado determinado pela necessidade e pela posse de recursos naturais para a conquista das condições de sobrevivência, por outro lado por sua ocupação física como habitat. Neste instante, na origem, a defesa territorial é exercida diretamente pelos membros da coletividade. Noutro extremo, como já ocorre desde a criação do Estado, quando há uma população fixada territorialmente e socialmente organizada para a produção de riquezas, cada indivíduo não mantém mais uma relação de domínio direto e repartido com o restante da coletividade sobre o território que habita. Assim, a defesa territorial passa a ser realizada por uma configuração social voltada exclusivamente à organização e à manutenção do poder. Machado (2005, p. 7) destaca que:

[...] analisar o território significa entendê-lo como um produto da história da sociedade, e que, portanto, está em constante modificação. Ele é o resultado de um processo de apropriação de um grupo social e do quadro de funcionamento da sociedade, assim, ao mesmo tempo, uma dimensão material e cultural dadas historicamente. A noção de território pode ser utilizada sem problemas, em todas as escalas de análise.

Observa-se que, historicamente, a concepção de território associa-se à idéia de natureza e a de sociedades configuradas por um limite de extensão do poder.

Na análise de Tuan (1980), a questão do território leva a reflexão sobre a sua formação para o ser humano, onde ele constrói o território como um lugar repleto de emoções e racionalidade, sendo capaz inclusive de idealizar o seu território como um espaço que se refere a uma grande carga 
emocional, atribuindo-lhe um grande sentimento de pertença.

O território em si não é um conceito. Ele só se torna um conceito utilizável para a análise social quando se considera o momento em que se pensa juntamente com aqueles atores que dele se utilizam (SANTOS, 2002).

Deste modo, as relações sociais, por sua diversidade, criam vários tipos de territórios, que são contínuos em áreas extensas e/ ou são descontínuos em pontos e redes, formados por diferentes escalas e dimensões. Os territórios são países, estados, regiões, municípios, departamentos, bairros, fábricas, vilas, propriedades, moradias, salas, corpo, mente, pensamento, conhecimento. Percebese, dessa forma, que a questão do território não está baseada apenas nas características geofísicas, mas, sobretudo, está baseado nas relações sociais, o que reproduz um espaço de manifestações e ações.

No aporte de Souza (1995, p. 78-96),

O território é fundamentalmente um espaço definido e delimitado por e a partir de relações de poder [...] o poder corresponde à habilidade humana de não apenas agir, mas de agir em uníssono, em comum acordo. $\mathrm{O}$ poder jamais é propriedade de um indivíduo; pertence ele a um grupo e existe apenas enquanto o grupo se mantiver unido [...] Assim como o poder é onipresente nas relações sociais, o território está, outrossim, presente em toda a espacialidade [...] territórios são construídos (e desconstruídos) dentro de escalas temporais as mais diferentes: séculos, décadas, anos, meses ou dias.

Essa afirmação salienta a importância das relações humanas em uma comunidade, pois são essas relações que irão compor os cenários do território. A interação entre os grupos nas comunidades é o caminho para a evolução do desenvolvimento local.

Neves (1998, p.271) entende território como:

[...] espaços de ação e de poderes, dentro de uma idéia de globalidade e vivência da fragmentação. O exercício do poder se daria sobre o 'conteúdo do espaço', transformando os territórios através das forças econômicas, mas em especial, através das raízes culturais, onde as imagens e os mitos não podem ser negligenciados.

Nesse sentido, Tuan (1976) exemplifica o território comparando o comportamento dos animais com o dos seres humanos. Para este autor, as atitudes humanas, quanto ao território, são semelhantes aos dos animais irracionais. Porém, a diferença é que os animais são menos carregados de emoções e pensamentos simbólicos. Assim sendo, o território para eles, é uma área não circunscrita, trata-se de caminhos em redes e lugares suscetíveis. Em contra partida, os seres humanos são capazes de cultivar o território como um conceito, considerar mentalmente sua forma, mesmo aquelas que não são totalmente perceptíveis.

Souza (1995) acrescenta que, na Geografia política, o território aparece como espaço concreto em si, com suas características naturais ou sociais construídas, sendo sustentado e apropriado por um grupo social e, ainda, é visto como algo criador de raízes e de identidade própria.

Observa-se, desta forma, que a importância que o território assume para a Geografia hoje repousa em seu significado concreto, o que envolve não apenas o aspecto físico ou material, mas também tudo o que uma sociedade pode comportar como ideal, como representações, sentimentos de vinculação, de comportamentos individuais ou de instituições que participam de uma organização espacial. A questão fundamental continua sendo a de saber como se organiza uma sociedade na relação com espaço.

\section{- Territorialidade}

A territorialidade afeta o comportamento humano em todos os níveis da atividade social e sua noção é estabelecida a partir do conceito ocidental de propriedade privada. Dessa forma, concebe-se a territorialidade como um conjunto de relações que se originam num sistema tridimensional sociedade-espaço-tempo, o que implica em analisar a territorialidade em função da apreensão das relações recolocadas no seu contexto.

Santos (1978) esclarece que a territorialidade refere-se às relações entre um indivíduo ou grupo social e o seu meio de referência, manifestando-se nas várias escalas geográficas de uma localidade, uma região ou um país e, dessa maneira, expressa um sentimento de pertencimento e um modo de agir no âmbito de um dado território. Perce- 
be-se, assim, que a territorialidade supõe o vivido territorial em toda sua abrangência e em suas múltiplas dimensões cultural, política, econômica e social. Como atributo humano, ela é primariamente condicionada por normas sociais e por valores culturais, que variam de sociedade para sociedade.

Castoríades (1993 citado por SOUZA, 1995, p. 101-105) assinala que:

[...] Como toda a construção da realidade é um instrumento de poder, a (re) ordenação territorial regional, pode ser instrumento de poder tanto para os atores locais do desenvolvimento, como para a dominação do território, quando realizado sem a efetiva participação local. [...] a perspectiva da territorialidade regional, deveria ser o horizonte utópico a ser buscado pelos grupos sociais de uma determinada região, ao serem desafiados num processo de (re) ordenação do território, ou de alavancagem do desenvolvimento regional. Isto porque, a autonomia constitui a base do desenvolvimento, este encarado como o processo de auto-instituição da sociedade rumo a mais liberdade e menos desigualdades.

Holzer (1997) argumenta que a territorialidade é a expressão dos comportamentos vividos, ou se preferido, da construção dos mundos pessoal e integrado, englobando o arrolamento do território com o desconhecido.

\section{- Políticas públicas}

Em seus primórdios, a ciência política considerava as políticas públicas quase exclusivamente como outputs do sistema político, o que justificava o fato de a atenção dos investigadores ter se concentrado inicialmente nos inputs, isto é, nas demandas e articulações de interesse. Por outro lado, antes que a análise de políticas públicas fosse reconhecida como uma subárea na disciplina, a ênfase dos estudos recaía como em larga medida ainda hoje, diga-se de passagem, nos processos de formação das políticas públicas, o que parece refletir o status privilegiado que os processos decisórios sempre desfrutaram junto aos profissionais da área. Em um segundo momento, contudo, a partir da década de 1950, passou-se à definição das próprias políticas públicas como unidade de análise, o que gradualmente conferiu desta- que aos aspectos dinâmicos do chamado policy process e aos distintos atores, estatais e não estatais, usualmente envolvidos (RADAELLI, 1995 apud FARIA, 2003).

Há quase vinte anos, discorrendo sobre políticas públicas, Demo (1979) expôs a problemática da situação nacional, fazendo um retrospecto dos ciclos da política social no Brasil. E, já naquele período, ele indagava a viabilidade da formação de uma sociedade menos desigual num país em desenvolvimento. Este mesmo autor afirmava que o processo de desenvolvimento não se concebe sem planejamento e que a redução das desigualdades não se dá por si só. Ele alertava que era preciso forçar o mercado a assumir padrões redistributivos, pois era necessário também intervir na realidade de maneira a alcançar um desenvolvimento com metas mais racionais e desejáveis, obtendo assim uma sociedade mais igualitária.

Observa-se que as políticas públicas no Brasil estão em curso. Diante disso, nota-se, a partir do inicio da década de 1980, um movimento, plenamente consciente, de pesquisadores, de agências de fomento e de organizações públicas, que atuam na área de planejamento ao proporem novas formas de elaboração das políticas públicas, em uma nova perspectiva do significado de desenvolvimento e com base em uma visão do papel do Estado que não pode ser confundido com o estadismo nem com o privatismo. $\mathrm{O}$ destaque deve ficar por conta das parcerias e solidariedade da sociedade civil, mantendo o Estado responsável pela condução do processo de formulação de políticas relativas ao desenvolvimento.

Para Becker (1995), essa nova perspectiva consiste em selecionar pontos para aplicação de forças e na política do desenvolvimento regional, cuja maior expressão é a prática dos pólos de crescimento. Para a construção do desenvolvimento humano sustentável, uma das principais estratégias consiste na formação dos recursos humanos para programar tais políticas. É imprescindível que as pessoas que irão conduzir esse processo tenham, além da qualificação adequada, o conhecimento da realidade na qual irão trabalhar e estejam preparadas para levar em consideração as crenças e valores da comunidade local. 
Dentre as principais características das políticas públicas, segundo Pereira (2000), encontram-se:

1) Existência de um conteúdo que orienta os recursos humanos e materiais na busca de determinados resultados, de forma que não pode ser confundida com um ato isolado;

2) A existência de convergência entre o conteúdo da política, os atores e os mecanismos disponíveis para sua execução.

Portanto, o papel do Agente de Desenvolvimento é estimular a construção do desenvolvimento municipal/local numa visão de auto-sustentabilidade, trabalhando de forma articulada em parcerias com os órgãos governamentais e outros segmentos da sociedade, ou seja, é preciso que haja uma melhor articulação entre as iniciativas no nível local e as mudanças no nível dos sistemas. Indivíduos e organizações locais devem ser capazes de iniciar e manter o desenvolvimento de sua própria comunidade.

\section{A comunidade de artesãos em Três Lagoas-MS}

A comunidade de artesãos de Três Lagoas-MS surgiu por iniciativa de três organizações locais: SEBRAE, Prefeitura Municipal e ACITL no dia 9 de novembro de 2002, a partir do Projeto Empreender, idealizado pela CACB e o SEBRAE Nacional com o objetivo de promover o associativismo e o cooperativismo como alternativa de união dos artesãos para a sustentabilidade e o desenvolvimento do grupo. A primeira reunião realizada no dia 19 de novembro de 2002 teve como participante somente uma artesã, representantes do SEBRAE, ACITL e a Consultora do SEBRAE Maria Luzia Lomba de Souza.

A sensibilização de participantes para o Núcleo Setorial de Artesanato foi feita com divulgações na mídia escrita e falada local e, também, buscou-se o apoio da Prefeitura, que fez um levantamento dos nomes de artesãos que participavam das festas locais como a Festa do Folclore (realizada no mês de Agosto) em que apresentavam seus trabalhos. Após a localização desses artesãos, uma nova reunião foi marcada.

Para a participação da reunião compareceram vinte e dois artesãos, que não se conheciam e se consideravam concorrentes por trabalharem com artesanato. Percebeuse que os participantes estavam encantados com o projeto, embora ainda não conseguissem visualizar os caminhos e os meios para colocar em prática as ações de divulgação dos trabalhos, qualificação da mão de obra, novas técnicas de confecções e a utilização de novas matérias primas. Observou-se, na fala dos participantes que a maioria não tinha disponível sequer a matéria-prima para confeccionar seus trabalhos.

- Feira de artesanato na Praça da Bandeira: uma revelação dos artistas locais

Após algumas reuniões, o grupo começou a se organizar, e para comemorar o Dia Internacional da Mulher (8 de março de 2002), foi organizada pela Associação Comercial e pela Prefeitura Municipal a $1^{\text {a }}$ Feira de Artesanato em Três Lagoas. Foi um grande desafio, porque muitos não tinham matéria-prima para confeccionar as peças e nem infra-estrutura adequada para a montagem do espaço onde aconteceria o evento

A feira foi realizada na Praça da Bandeira ao ar livre e, mesmo com todas as dificuldades de infra-estrutura, segundo o jornal do povo, foi um sucesso (março/2002). Conforme os relatos em ata feita pelos artesãos, os elogios dos visitantes foram satisfatórios, pois a maioria dos moradores de Três Lagoas ainda não conhecia os trabalhos dos artesãos e nem se quer sabia que existiam. Devido ao sucesso, foi estabelecido que os artesãos apresentassem seus trabalhos sempre no segundo sábado de cada mês em espaço público

Como parte do aprimoramento proposto pelos representantes do projeto, os artesãos começaram a expor suas peças em vários locais da cidade, como: Exposição Agropecuária de Três Lagoas, na Faculdade AEMS, Expo Mulher; Pousada do Tucunaré; $18^{\mathrm{a}}$ Festa do Folclore. Essas exposições e feiras possibilitaram participações em outras cidades da região, ora vendendo os produtos ora visitando as feiras para adquirir novos conhecimentos. Dentre os eventos participados estão a Exposição Agropecuária de Andradina; a $1^{\text {a }}$ Feira do Artesanato em Brasilândia; a viagem para Campo Grande na Caravana MS Faz Tecnologia e a viagem de aprimoramento técnico para Naviraí 
- Ação de coordenação e aspectos do grupo de artesãos, e dos empresários locais

As feiras na Praça continuaram e a partir do desempenho dos integrantes do projeto, os empresários locais doaram cinco barracas, protegendo assim os trabalhos da chuva e do sol. Pouco a pouco, as feiras foram ficando mais organizadas e com maior qualidade dos produtos, atendimento e novo visual.

Os artesãos receberam treinamentos por meio de cursos específicos como: liderança, desenvolvimento interpessoal, formação de preço, motivação, qualidade no atendimento, solidariedade e reciprocidade, dentre outros. Essa iniciativa foi fundamental para a conscientização, aprimoramento técnico e criação de uma comissão com tesoureiro, secretaria, e sub-coordenação, já que a coordenação geral cabia à consultora Maria Luzia Lomba de Souza. O mandato da comissão duraria seis meses podendo ser alterado conforme a atuação dos artesãos escolhidos.

Além de receberem a doação das barracas, os artesãos do projeto passaram a ter um espaço para vender suas peças com a doação do espaço por uma das integrantes do projeto, Ana Viturino. Entretanto, o ponto era longe do centro comercial dificultando a locomoção dos compradores e dos artesãos na reposição dos produtos. Com o tempo deixaram de levar o artesanato e o local foi desativado.

- Identidade e autonomia do grupo: Criação da Atar - Associação Três-lagoense de Artesãos

Durante o apoio dos parceiros e da consultora os agentes enfatizavam que o sucesso só dependia deles e que a confiança, a solidariedade e a participação desenvolvidas entre eles eram fundamentais nessa caminhada. Em outubro de 2004 as parcerias chegaram ao fim e o núcleo de artesãos teria que continuar sozinho, mas antes a consultora do núcleo de artesanato sugeriu que escolhessem uma liderança, um representante, e elegeram a irmã Zélia Lopes da Silva (freira) como líder, ocasião em que obteve $96 \%$ da votação, pois desde o começo do projeto ela se fez presente e atuante. A Irmã
Zélia é uma das grandes responsáveis pela continuidade da comunidade de artesãos depois da saída da consultora Maria Luzia do Projeto Empreender. Conforme ressalta Boog (1999), para ser um bom líder é preciso fazer com que os outros tenham vontade de fazer algo que eles estejam convencidos de que deve ser feito.

A comunidade se tornou uma a Associação Três-lagoense de Artesãos - ATAR, contando com 38 associados que desenvolvem os mais variados tipos de trabalhos manuais, como pintura, retalhos, costuras, bordados, tecelagem, madeira, arte em jornal, meia de seda, mosaicos, crochês, entre outros e recentemente, foi inaugurada uma nova sede na Av. Ranulpho Marques Leal. Neste momento, o grupo também está mais amadurecido para manter esse empreendimento. Diferente da situação anterior, a ATAR arca com as despesas de aluguel e da manutenção do estabelecimento.

Segundo Massunari (2006), o artesanato na cidade de Três Lagoas desenvolve um papel relevante na sociedade local, já que, além da expressão artística e cultural, gera trabalho e renda para uma parte da população, fazendo-se um meio de vida para uns e um equilíbrio no orçamento familiar para outros. Nesse contexto, as peças artesanais, têm se detacado como verdadeiros ícones da cidade e até mesmo do Estado.

\section{Análise e interpretação dos dados coletados}

A pesquisa de campo foi realizada via entrevistas estruturadas e questionários na sede da comunidade de artesãos na cidade de Três Lagoas-MS com vinte e cinco artesãos. O processo da pesquisa caracterizouse pela interação dos seguintes elementos: questão básica da pesquisa, o que motivou a investigação. Quanto aos sistemas conceituais foram utilizados para interpretar os fenômenos e utilizaram-se métodos específicos para coletar, registrar e transformar os dados. Na análise foi utilizado o método de porcentagem e números absolutos na apresentação dos resultados obtidos nos questionamentos, pois o questionário possibilitou a população alvo mais de uma alternativa em algumas questões. 
A comunidade de artesãos é formada por $92 \%$ (23 artesãs) de mulheres e apenas $8 \%$ (dois artesãos) de homens, verificandose que a sociedade ainda considera o artesanato como uma atividade feminina. Dos informantes $16 \%$ (quatro artesãos) possuem o ensino fundamental; $60 \%$ (15 artesãos) o ensino médio; $12 \%$ (três artesãos) ensino superior e $12 \%$ (três artesãos) possuem pósgraduação. Observa-se que a base educacional da comunidade está equilibrada, em que, segundo elas, várias artesãs são professoras aposentadas. Isso mostra que, ao contrário do que se pensava, que nem todas as comunidades de artesãos são formadas por pessoas carentes e analfabetas. A educação escolar (primário, secundário e superior) constitui a base para diferentes patamares de qualificação. Nessa concepção, portanto, o grau de escolaridade formal constitui um dos principais ingredientes do processo de consolidação da comunidade.

Manfredi e Bastos (1997) salientam que a sociedade que queremos construir antecipa-se na escola como possibilidade desejável e realizável através de iniciativas de solidariedade, participação e de exercício de governo compartilhado.

Quanto à renda familiar mensal, sem contar a renda com o artesanato, observouse que $4 \%$ (um artesão) tem renda mensal de um salário mínimo, 68\% (17 artesãos) possuem renda mensal de dois a quatro salários e $28 \%$ (sete artesãos) têm renda mensal acima de quatro salários mínimos. Nem todos os integrantes da comunidade são casados ou têm a necessidade de contribuir com a renda familiar, o que justifica a porcentagem de um salário mínimo. Constatou-se que $68 \%$ receberam de dois a quatro salários mínimos e $28 \%$ acima de quatro salários. Justifica-se tal índice pelo grau de escolaridade desses artesãos, já que uma grande parcela deles são professores(as) aposentados(as).

Quando questionados porque confeccionavam artesanato; identificou-se 10,81\% (quatro artesãos) foi por influência familiar; $18,92 \%$ (sete artesãos) ingressaram na atividade por curiosidade, 13,51\% (cinco artesãos) receberam convite de outros artesãos, 45,95\% (17 artesãos) para complementar a renda familiar (representando quase a metade da população pesquisada) e 10,81\% (quatro artesãos) atribuíram a outros fatores. Informaram também que $6,25 \%$ (dois artesãos) tomaram conhecimento do artesanato por meio da mídia; $65,62 \%$ (21 artesãos) por meio de convites de outros artesãos; $18,75 \%$ (seis artesãos) a partir de eventos realizados e 9,38\% (três artesãos) pelos agentes do Projeto Empreender. Vale lembrar que nesta questão os questionados responderam mais que uma alternativa.

A falta de participantes na primeira reunião deu origem a várias estratégias para que os artesãos locais se interessassem pela comunidade. Uma delas foi à veiculação do projeto na mídia com o objetivo de convidar pessoas que tinham conhecimento sobre a atividade. Outra maneira foi à divulgação boca a boca feita pelos envolvidos a fim de propagar o projeto à comunidade. Vale destacar que dentre os métodos este foi o mais eficaz.

A venda do artesanato, segundo os informantes, proporciona uma rentabilidade de menos de um salário mínimo para 92\% (23 artesãos), de um salário mínimo para $4 \%$ (um artesão) e entre dois e quatro salários para $4 \%$ (um artesão). A atividade não garante uma rentabilidade satisfatória que segundo os artesãos se dá pelo fato da venda do artesanato depender da sazonalidade, ou seja, em algumas feiras, as apresentações dos trabalhos em épocas festivas, como por exemplo: páscoa, dia das mães, dia dos pais e natal onde nem sempre todos vendem produtos de forma igualitária. Verifica-se, dessa forma, que a atividade não pode ainda ser considerada como um meio de vida para esses artesãos, pois necessitam de outra fonte de renda para sobreviver. Por outro lado, na questão sobre a influência familiar referente ao ofício de artesão, assinalaram que devem dar possibilidade de trabalho às gerações mais novas, que devem receber das mais velhas as técnicas e demais experiências acumuladas, porém, cada um deve acentuar às peças o seu cunho de originalidade pessoal.

A pesquisa apontou que as principais dificuldades enfrentadas pela atividade artesanal são: a escassez de recursos financeiros com 21,15\% (11 artesãos), a qualidade da matéria-prima com $13,46 \%$ (sete artesãos). O mercado para o artesanato apresen- 
tou $36,54 \%$ (19 artesãos) como dificuldade e quando questionado sobre o grau de satisfação do mercado responderam que o mercado do artesanato é ótimo com 18, $8 \%$ (dois artesãos); muito bom com $4 \%$; (um artesão) bom com $24 \%$ (seis artesãos); regular com $48 \%$ (12 artesãos) e atribuíram como ruim16\% (quatro artesãos). Outra dificuldade atribuída diz respeito à falta de incentivo governamental, apresentando 21,15\% (11 artesãos), e apenas 7,70\% (quatro artesãos) caracterizam a falta de relacionamento interpessoal. É importante destacar que o município de Três Lagoas-MS ainda não se caracteriza como uma cidade turística e a sociedade local ainda não valorizam e nem é estimulada a adquirir produtos confeccionados pelos artesãos, o que justifica a falta de mercado apontada pelos informantes.

Outras preocupações segundo os informantes são a falta de espaço físico para comercialização do artesanato com 52\% (13 artesãos), desunião dos integrantes com $24 \%$ (seis artesãos), cooperação e custo da matéria prima com $8 \%$ (dois artesãos); falta transporte próprio para transportar os artesanatos para as feiras e eventos com $4 \%$ (um artesão) e a imposição da liderança sobre as atividades executadas pelo grupo também com $4 \%$ (um artesão).

Baseando-se nas colocações de Martins (1973), percebe-se que o regime de trabalho manual necessita de um estímulo vigoroso e pertinaz para se desenvolver, sendo que isto só se conseguirá mediante uma ação da comunidade, da sociedade local e do governo municipal. Não convém que essa ajuda se faça de maneira ostensiva, mas cautelosa. Desse modo, qualquer plano de proteção ao artesanato deve preceder de estudos bem dirigidos e deve ser elaborado com a convicção plena dos bons resultados que serão obtidos e segundo os objetivos a que se tem em vista alcançar.

A atividade artesanal está ligada ao estilo de vida e do grau de comércio com comunidades vizinhas, sendo o artesanato uma manifestação da vida comunitária. Sobretudo, a comunidade deve ser orientada no sentido de produzir objetos de uso mais comum no lugar, seja em função utilitária, lúdica, decorativa ou religiosa, portanto, é preciso pesquisar quais os produtos que o mercado deseja comprar.
Quanto aos artesanatos confeccionados $42,10 \%$ (24 artesãos) responderam que os produtos são comercializados em feiras realizadas na Praça da Bandeira; 29,83\% (17 artesãos) em feiras livres; $22,80 \%$ (13 artesãos) nas residências; 5,27\% (três artesãos) comercializam no ponto de venda. Para as vendas ambulantes não houve porcentagem. Observou-se que as feiras realizadas na praça exercem um papel fundamental na venda dos artesanatos, mas a venda nas residências representa valor significativo que precisa ser estudado como uma ferramenta. Segundo os artesãos a venda de porta em porta significa clientela fixa, o que sugere uma segurança na sua rentabilidade. Esses mesmos clientes indicam que os produtos para amigos e familiares têm aumentando o potencial de venda desses artesãos. Já a comercialização na loja, conforme aponta a pesquisa, não representa um número expressivo $(5,27 \%)$. Vale lembrar que o local destinado à venda foi inaugurado recentemente, não se localiza em ponto estratégico comercial tornando a venda mais lenta.

Quando questionados sobre o conhecimento na formação de preço do artesanato, $14 \%$ (sete artesãos) responderam que sim, 28\% (14 artesãos) conhecem as formas de comercialização; 8\% (quatro artesãos) têm conhecimentos básicos sobre pesquisa de mercado; 26\% (13 artesãos) fizeram cursos sobre a qualidade dos artesanatos e $24 \%$ (12 artesãos) têm conhecimento sobre relacionamento interpessoal. Isso se da pelo fato dos cursos e treinamentos ao longo do processo do projeto - Desenvolvimento Empreendedor.

Conforme salienta Harbison (1974), as transformações em curso na sociedade brasileira, decorrentes das mudanças técnicoorganizacionais no mundo do trabalho, estão fazendo ressurgir, com muita ênfase, entusiasmados debates relativos a temas e problemas que nos remetem às relações entre trabalho, qualificação e educação (especialmente a formação profissional). A expressão "formação de capital humano", empregada por Harbison (1974), significa o processo de formação e incremento do número de pessoas que possuem as habilidades, a educação e a experiência indispensáveis para o desenvolvimento. 
Conforme explica Manfredi (1998), os trabalhadores como sujeitos coletivos, estariam também se construindo e se qualificando, apesar das condições alienantes e alienadoras do trabalho sob a égide e o controle do capital. Sobretudo, a preparação técnica é considerada importante, mas é entendida como uma dentre as várias dimensões a serem valoradas no processo educativo. É importante destacar que a técnica não é instância separada da cultura de uma sociedade.

Analisando os dados coletados observou-se que $57,58 \%$ (19 artesãos) dos informantes adquiriram esses conhecimentos através do SEBRAE; 12,12\% (quatro artesãos) foram treinados pela consultora do Projeto Empreender na sede ACITL onde eram realizadas as reuniões; 9,09\% (três artesãos) através da participação em cursos oferecidos pela Prefeitura Municipal e 21,21\% (sete artesãos) através de outras fontes como pesquisas realizadas em revistas especializadas, jornais, colegas da própria comunidade e cursos promovidos por escolas técnicas. Quando questionados sobre o grau de classificação quanto a participação no desenvolvimento da comunidade de artesãos $20 \%$ (cinco artesãos) atribuíram como ótima, 16\% (quatro artesãos) como muito boa, 28\% (sete artesãos) como boa e 36\% (nove artesãos) como regular. As maiores reclamações apontadas por eles dizem respeito à falta de atenção para a comunidade e um local para a comercialização do produto do qual o Sebrae e a ACITL não podem resolver, pois seu papel é de capacitação para a gestão local, com a possibilidade de realizar diagnósticos, elaborar e executar projetos, monitorar e avaliar os resultados e capacitação.

A pesquisa mostrou que em todos os anos houve um aumento na entrada de novos participantes à comunidade de artesãos, onde $12 \%$ (três artesãos) dos informantes fazem parte da comunidade desde seu início em 2002; 20\% (cinco artesãos) ingressaram entre 2002 e 2003; 16\% (quatro artesãos) em 2003 e 2004; 32\% (oito artesãos) ingressaram entre 2004 a 2005 e $20 \%$ (cinco artesãos) ingressaram em 2006. Isso se deve ao fato de que o progresso dos trabalhos e o reconhecimento do grupo cada vez mais têm aumentado. Porém, verifica-se que, no período de 2003 a 2004, houve um declínio no percen- tual. Segundo os dados obtidos através das documentações transpostas em ata, foi neste período que tiveram fim as parcerias entre o SEBRAE e a ACITL que durou dois anos. Nesse momento, eles precisaram colocar em prática todos os ensinamentos que os agentes passaram, principalmente, sobre motivação pessoal, pois dependeria de cada um a continuidade do trabalho. Esse processo os levou a desenvolver a solidariedade, o sentimento de pertença e a identidade coletiva.

Com isso, em 2005, a comunidade se reafirmou e obteve um aumento no percentual de integrantes perdurando em 2006, conforme mostra a pesquisa.

Observou-se que 40\% (10 artesãos) responderam que a comunidade coopera e interage entre si; $4 \%$ (um artesão) responderam que não; 56\% (14 artesãos), ou seja, mais da metade responderam que às vezes há interação e cooperação entre a comunidade. Foi levantado também que 72\% (18 artesãos) participaram das atividades da comunidade e $28 \%$ (sete artesãos) participaram às vezes.

Evidencia-se que a participação dos integrantes não é totalmente efetiva. Segundo os relatos, os objetivos individuais ainda prevalecem sobre os grupais. A cooperação dos integrantes oscila conforme o benefício que terá com aquela ação. Em dias de apresentações em feiras, esse fator se sobressai ainda mais; uma vez que todos querem o lucro. Porém, são poucos que contribuem para a realização das atividades. Segundo eles, este é um dos grandes problemas enfrentados pela comunidade.

Conforme assinala Fritzen (1980), as relações entre as pessoas continuam sendo motivos de grandes conflitos e muitas dificuldades. As diferenças de valores, experiências, percepções e opiniões são diversas e essas diferenças estão vivamente presentes na comunidade e em suas interações pessoais, influenciando cada ação, pensamento e decisão. A cooperação é uma filosofia baseada em conceitos e valores humanísticos, como solidariedade, confiança e organização funcional de grupos. Tem como propósito substituir o individualismo pela ação coletiva.

Quanto ao artesanato confeccionado, os percentuais não atingiram $100 \%$ porque nesse quesito, além das criações serem muito diversificadas, os pesquisados respondeu 
mais de uma alternativa. Assim, os dados coletados foram: 8,64\% (sete artesãos) biscuit; 7,40\% (seis artesãos) tapetes; $6,17 \%$ (cinco artesãos) bonecas; $2,47 \%$ (dois artesãos) licor; 9,88\% (oito artesãos) bolsas; $13,59 \%$ (11 artesãos) pano de prato e bordados em geral; 6,17\% (cinco artesãos) animais de vários materiais; $6,17 \%$ (cinco artesãos) bijuterias; $3,70 \%$ (três artesãos) artefatos em jornal; $9,88 \%$ (oito artesãos) objetos de cerâmica; 4,94\% (cinco artesãos) pintura em tela; $7,40 \%$ (seis artesãos) artefatos de madeira e 13,59\% (11 artesãos) trabalhos com meias de seda, crochê, mosaico, decopagem, sabonetes, velas decorativas e bolachas. Há uma grande diversificação de artesanatos onde o artesão, geralmente, domina várias técnicas do artesanato, favorecendo, assim, a diversidade no mercado consumidor. Cabe ressaltar que todos eles continuam fazendo cursos para o aprimoramento das técnicas. Esses cursos são feitos particularmente ou realizados a partir das parcerias com o SEBRAE e a Prefeitura Municipal.

\section{Considerações finais}

O desenvolvimento local tem sido motivo de intenso estudo entre os profissionais das áreas de Economia, Administração, Sociologia, Política, Antropologia, Geografia e História. A partir da crise econômica no final dos anos 70 e começo dos 80, mudou-se a discussão sobre o desenvolvimento de uma visão global para uma visão local, logo, mais apropriada para as comunidades.

A construção dos conceitos de desenvolvimento local e políticas públicas é um processo amplo e de debate permanente como nova maneira de promover o desenvolvimento contribuindo para: melhoria da qualidade de vida das comunidades dos municípios, surgimento de comunidades sustentáveis, capacidade de suprir suas necessidades mais imediatas, despertar ou descobrir suas vocações, expandirem suas potencialidades e incrementar o intercâmbio externo aproveitando-se de suas vantagens locais. Juntamente, a construção e a formação da identidade local, as questões econômicas, sócio-culturais e ambientais, a participação de atores sociais, as novas territorialidades criadas na distribuição/in- tegração espacial do desenvolvimento, as novas estratégias de políticas locais, têm sido re-interpretados a partir de novos conceitos e modelos de análise.

Os princípios do desenvolvimento local buscam atuar, dirigindo os esforços e as atividades nas comunidades, com enfoque nos conceitos de identidade, cooperação e solidariedade. A necessidade da solidariedade vai readaptando ou redefinindo as vocações locais como um conjunto de potencialidades não apenas econômicas, mas também de condições sócio-culturais e ambientais, que possam garantir a manutenção dos atores econômicos presentes e a qualidade de vida das populações no desenvolvimento local.

A capacitação da comunidade pelos atores externos locais constitui a alma de todo o processo. Nada será feito se a comunidade não for capacitada para a gestão local, isto é, se não aprender a fazer diagnósticos, elaborar, executar, monitorar e avaliar projetos, prestar contas, articular atores externos, programar e negociar interesses e opiniões diversas e, ainda, animar a comunidade no seu processo de emancipação. $\mathrm{O}$ processo de capacitação deverá ser inicialmente por meio da sensibilização dos participantes da comunidade estudada e, posteriormente, por treinamentos.

O comportamento dos artesãos, a percepção das políticas e as mudanças não são automáticas. A aprendizagem é um processo de médio e longo prazo, constituindo-se em oportunidades concretas de desenvolvimento. No entanto, verificou-se com o estudo que na comunidade de artesãos de Três Lagoas-MS a falta de: espaço físico para a venda os produtos, mercado para os produtos, recursos financeiros, divulgação dos produtos e a dependência dos agentes externos, relação interpessoal são fatores que dificultam o desenvolvimento da comunidade de artesãos no local.

Para que esses fatos sejam revertidos deve-se fomentar a cultura da cooperação e da confiança entre os membros da comunidade, realizar treinamentos e capacitação gerencial, para que elas dependam pouco dos agentes externos, governos e associações de classe e assim consigam definir sozinhos aonde, como e quando atingir a auto-suficiência do grupo. 


\section{Referências}

BECKER, Bertha K.; CASTRO, Iná Elias et al. (orgs.). Geografia, conceitos e temas. Rio de Janeiro: Bertrand Brasil, 1995.

BOOG, Gustavo G. (Coord.). Manual de treinamento e desenvolvimento. 3. ed. São Paulo: Makron Books, 1999.

CORREAA, Roberto Lobato. Território e corporação: um exemplo. In: SANTOS, Milton; SOUZA Maria Adélia D. de e SILVEIRA Maria Laura (org.). Território, globalização e fragmentação. São Paulo: Hucitec, 1994.

DEMO, Pedro. Formação profissional e desenvolvimento econômico/social. I SEMINÁRIO NACIONAL DE POLÍTICA E PLANEJAMENTO. FGV: SENAC/DN, 1979.

FARIA, Carlos Aurélio Pimenta de. Idéias, conhecimento e políticas públicas: um inventário sucinto das principais vertentes analíticas recentes. Revista Brasileira de Ciências Sociais, São Paulo, v.18, n.51, fev. 2003.

FRAGOSO, Antônio. Contributos para o debate teórico sobre o desenvolvimento local: um ensaio baseado em experiências investigativas. In: Revista Lusófona de Educação, n. 5, p. 63-83, 2005.

FRITZEN, José Silvino. Exercícios práticos de dinâmica de grupo e de relações humanas. Petrópolis: Vozes, 1980.

HARBISON, Frederick H. Mão-de-obra e desenvolvimento econômico: problemas e estratégia. In: PEREIRA, Luiz (org.). Desenvolvimento, trabalho e educação. 2. ed. Rio de Janeiro: Zahar, 1974.

HEIDRICH, A. Fundamentos da formação do território moderno. Boletim Gaúcho de Geografia, AGB - Seção Porto Alegre, n. 23, 1998.

HOLZER, Werther. Uma discussão fenomenológica sobre os conceitos de paisagem e lugar, território e meio ambiente. Território, Rio de Janeiro, ano II, n.3, jul./dez. 1997.

KLIKSBERG, Bernardo. Falácias e mitos do desenvolvimento social. Tradução: Sandra Trabucco Valenzuela, Silvana Cobucci Leite. 2. ed. São Paulo: Cortez, 2003.

MACHADO, M. S. Geografia e epistemologia: um passeio pelos conceitos de espaço, território e territorialidade. Disponível em: www.bdmdl.ucdb.br, 5/9/2005.

MANFREDI, Silvia Maria; BASTOS, Solange. Experiências e projetos de formação profissional entre trabalhadores brasileiros. Educação \& Sociedade, ano XVIII, n. 60, dez. 1997.

MANFREDI, Silvia Maria. Trabalho, qualificação e competência profissional: das dimensões conceituais e políticas. Educação \& Sociedade, Campinas, v.19, n.64, set. 1998.

MARTINS, Saul. Contribuição ao estudo científico do artesanato. Belo Horizonte: Imprensa Oficial do Estado de Minas Gerais, 1973.

MARTINS, Sérgio R.O. Desenvolvimento local: questões conceituais e metodológicas. Interações - Revista Internacional de Desenvolvimento Local, Campo grande: UCDB, v.3, n.5, p. 51-59, set. 2002.
MASSUNARI, Laura. Associação Três-lagoense de artesãos inaugura sede para comercializar trabalhos. Jornal do povo, Três Lagoas, 10 jun.2006, p.16.

NEVES, Gervásio Rodrigo. Territorialidade, desteritorrialidade, novas territorialidades: algumas notas. In: SANTOS, Milton; SOUZA Maria Adélia D. de; SILVEIRA, Maria Laura (org.). Território, globalização e fragmentação. 4. ed. São Paulo: Hucitec, 1998.

PEREIRA, Luiz Carlos Bresser. Desenvolvimento e crise no Brasil. São Paulo: Brasiliense, 1985.

PEREIRA, Potyara A. P. Necessidades humanas: subsídios á crítica dos mínimos sociais. São Paulo: Cortez, 2000.

RAFFESTIN, Claude. Por uma geografia do poder. Tradução: Maria Cecília França. São Paulo: Ática, 1993.

SACK, Robert David. Territorialidade humana: teoria e história. Cambridge: Cambridge University Press, 1986.

SANTOS, Milton. Por uma geografia nova. São Paulo: Hucitec, 1978.

. Técnica, espaço e tempo. São Paulo: Hucitec, 1994.

. O retorno do território. In: SANTOS, Milton; SOUZA Maria Adélia D. de; SILVEIRA, Maria Laura (org.). Território, globalização e fragmentação. 5. ed. São Paulo: Hucitec, 2002.

Território e sociedade. 2. ed .São Paulo: Hucitec, 2002.

SOUZA, Marcelo José Lopes de. O território sobre espaço e poder, autonomia e desenvolvimento. In: CASTRO, Iná Elias de et al. (org.). Geografia: conceitos e temas. Rio de Janeiro: Bertrand Brasil, 1995.

TUAN, Yi-Fu. Geografia humanística. Anais... da Associação de Geógrafos Americanos, v.66, n.2, jun./1976.

Topofilia. São Paulo: Difel, 1980.

1997.

MARTINELL, Alfons. Cultura e cidade: uma aliança para o desenvolvimento. A experiência da Espanha. In: COELHO, T. (org.). Políticas culturais para o desenvolvimento: uma base de dados para cultura. Brasília-DF: UNESCO Brasil, 2003.

SACHS, Ignacy. Ecodesenvolvimento: ecologia e desenvolvimento 1972 -1992. In: MAIMON, Dália (org.). Ecologia e desenvolvimento. Rio de Janeiro: APED, 1992.

SANTOS, Boaventura de Sousa (org.). A globalização e as ciências sociais. São Paulo: Cortez, 2002.

TAUK SANTOS, Maria Salett. Comunicação rural velho objeto, nova abordagem, mediação, reconversão cultural, desenvolvimento local. In: LOPES, M.L.V. de; FRAU-MEIGS; TAUK SANTOS, M.S. (orgs.). Comunicação e informação: identidades sem fronteiras. São Paulo: Intercom; Recife: Bargaço, 2000.

TAUK SANTOS, Maria Salett; CALLOU, Angelo Brás Fernandes. Desafios comunicação rural em tempo de desenvolvimento local. Revista Signo, João Pessoa, ano 2, n. 3, set. 1995. 